\title{
Generalized Predatory Impact Model: A Numerical Approach for Assessing Trophic Limits to Hatchery Releases and Controlling Related Ecological Risks
}

\author{
MATTHEW D. TAYLOR, ${ }^{1,2}$ NATHAN P. BRENNAN, ${ }^{3}$ KAI LORENZEN, ${ }^{3,4}$ \\ and KENNETH M. LEBER ${ }^{3}$ \\ ${ }^{1}$ Wild Fisheries Research, Port Stephens Fisheries Institute, NSW Department of Primary Industries, Nelson Bay, New South \\ Wales, Australia \\ ${ }^{2}$ School of Biological, Earth and Environmental Sciences, University of New South Wales, Sydney, \\ New South Wales, Australia \\ ${ }^{3}$ Center for Fisheries Enhancement, Mote Marine Laboratory, Sarasota, Florida, USA \\ ${ }^{4}$ Fisheries and Aquatic Sciences, School of Forest Resources and Conservation, University of Florida, \\ Gainesville, Florida, USA
}

\begin{abstract}
Rigorous assessment of species and ecosystem biology underpins responsible marine stock enhancement. Estimation of limits to stocking density, based on ecosystem productivity and energetic requirements of stocked species, can be used to gauge the appropriate magnitude of release densities, minimizing waste of resources, and the possibility for adverse stocking effects. A generalized mass-balance model (generalized predatory impact model) for stocking density estimation has been developed. The approach is based around the principles of ECOPATH and accounts for dynamic estimation of stocking-related ecosystem relationships at fine temporal (days) and spatial scales. The main parameter inputs include probability distributions for key biological and life-history traits of stocked species and estimates of primary productivity for the target ecosystem. The energetic requirements of stocked fish are evaluated in terms of growth and mortality as well as ontogenetic transitions in diet, habitat use, morphology, and migration. The theoretical carrying capacity for a stocked species within a given arena is assessed from primary productivity, levels of predation by stocked fish on different trophic groups, and a specified level of acceptable trophic impact. A Monte Carlo analysis of uncertainty is used to provide a probability distribution of stocking densities for a given trophic impact. The model is applied for stocking juveniles of snook (Centropomus undecimalis) in Sarasota, FL, USA, and mulloway (Argyrosomus japonicus) in Georges River, NSW, Australia. The model is useful for estimating an appropriate stocking density when planning pilot-scale fish releases. Such releases should be carefully monitored to validate model assumptions and determine density-dependent and other environmental effects.
\end{abstract}

Keywords trophic impact, trophic level, stocking density, mortality, common snook, mulloway

\section{INTRODUCTION}

Increasing pressure on fish stocks worldwide is well documented and is reflected by declining fishery catch relative to

Address correspondence to Matthew D. Taylor, School of Biological, Earth and Environmental Sciences, University of New South Wales, Sydney, NSW, 2052, Australia. E-mail: matt.taylor@dpi.nsw.gov.au effort (e.g., Cook et al., 1997; Pauly et al., 2002; Sibert et al., 2006). The long-accepted maximum yearly fisheries production of 80 million tonnes (Gulland, 1970) was exceeded in the late 1980s, and total production has stabilized at around 90 million tonnes since 1990, despite continually increasing effort and improved technology. In reality, while worldwide production has stabilized, continuing increases in fishing effort carry a risk of stock declines and decreased economic productivity 
(Beddington et al., 2007). Stock enhancement, sea ranching, or restocking provides an opportunity to increase fishing productivity in some situations through the release of hatchery-reared recruits (Bell et al., 2008).

The release of cultured individuals into estuarine and marine systems is an old concept. Historically, the process has been fraught with many failures where releases were ineffective or had detrimental impacts on wild populations, but there have also been also some fisheries and conservation successes (Hilborn, 1998). Many past failures have arisen due to an incomplete understanding of the ecosystem, the target species, or the fishery, which have led to release programs being developed in inappropriate systems or being operated inefficiently (Taylor et al., 2005). Nonetheless, current concerns about depletion of fish stocks and degradation of aquatic habitats have stimulated a resurgence of interest in fisheries enhancement, and many research programs aimed at responsible implementation of fish releases have emerged in recent years (Bell et al., 2008). Whether releases occur for the purposes of sea ranching, stock enhancement, or re-stocking, the success of such programs is clearly linked to the capacity of the environment to support additional hatchery-reared recruits.

The assumption that recruitment may be limited to a level that does not fully utilize the available carrying capacity is central to stocking-related activities, and this has been addressed at length in the literature (Munro and Bell, 1997; Doherty, 1999; Walters and Martell, 2004; Taylor et al., 2005; Bell et al., 2006). Despite this assumption, carrying capacity is rarely assessed in a quantitative fashion prior to the release of fish, although a limited number of case studies have examined carrying capacity in the context of stock enhancement (Leber et al., 1995; Salvanes et al., 1995; Cooney and Brodeur, 1998; van der Veer et al., 2000; Brennan et al., 2008). Blankenship and Leber (1995) suggested that the carrying capacity of a particular habitat be assessed through pilot releases and subsequent monitoring of density-dependent responses (such as growth, survival, and emigration). While this approach forms an integral component of the responsible approach to marine stock enhancement, the full extent of density-dependent processes, and thus the carrying capacity, will only become evident when high levels of releases are tested. The risk of overstocking therefore remains a concern, particularly where adverse ecological consequences could include displacement of wild stock and other competitors.

The development of detailed, system-specific models of carrying capacity is often beyond the scope of most pilot-scale marine releases. In addition, this may be difficult to estimate where stocking aims to fill the carrying capacity produced when the natural supply of juveniles has failed or is reduced (Stottrup and Sparrevohn, 2007). Consequently, there is a clear need for an approach for establishing release densities for pilot releases, especially when releases are targeted to smaller systems (Taylor and Suthers, 2008). This is particularly important when stocking high-level predators, where there is a potential to have broad impacts across a range of lower trophic levels. It is important to both evaluate these potential effects and the significance of density-dependence in the proposed stocking scenario.

The predatory impact model (PIM) is a decision support tool that was initially designed to estimate the trophic impacts associated with stocking mulloway (Argyrosomus japonicus) in the Georges River and to use these values to inform stocking density estimation (Taylor and Suthers, 2008). While the PIM is specific for mulloway, the concept was designed using general relationships published in the scientific literature and relatively minor data requirements that would allow application to other species and systems. This article describes the structure of a generalized version of the PIM (GPIM) and demonstrates application of the model to case studies for mulloway releases in New South Wales, Australia, and snook (Centropomus undecimalis) releases in Florida, USA.

Argyrosomus japonicus is an estuarine and coastal predator distributed across the Indian Ocean basin and the western Pacific Ocean (Silberschneider and Gray, 2008; Taylor and Piola, 2008). Mulloway is a carnivore, with small juveniles preying on mysid shrimp common in estuarine habitats (Taylor, 2008); larger juveniles prey on penaeid prawns, and adults primarily prey on zooplanktivorous fishes (Taylor et al., 2006a; Taylor and Mazumder, 2010). The species inhabits inshore and near-shore areas (Taylor et al., 2006b), is fast growing, matures from $51 \mathrm{~cm}$ total length (TL), and is currently classified as overfished in New South Wales (Silberschneider et al., 2009). Research into the development of stock enhancement for the species has been underway across several estuaries (Taylor et al., 2009). Common snook (Centropomus undecimalis; hereafter referred to as snook) are a coastal warm-water fish of economic importance, which commonly associate with shoreline habitat (Peters et al., 1998). Small snook prey predominantly on small crustaceans, with fish (including anchovies and small sparids) prevalent in the diet from a length of $30 \mathrm{~cm}$ (Blewett et al., 2006). Decapod crustaceans, such as penaeid shrimp and portunid crabs, are present in the diet throughout the juvenile stage (Gilmore et al., 1983; McMichael et al., 1989); however, when snook reach maturity, the diet is almost exclusively composed of fish (Blewett et al., 2006). Snook represent one of the top marine sport fish along the Florida coastline (Muller and Taylor, 2006) but are considered overfished (Muller and Taylor, 2006). In addition, fishing mortality rates have continued to increase alongside declining recruitment rates over previous decades, despite strict catch regulations (Muller and Taylor, 2006). This is in part due to catch-and-release mortality, which accounts for a substantial portion of fishing mortality (Taylor et al., 2001; Muller and Taylor, 2006). Stock enhancement research to augment low levels of natural recruitment for snook off Florida's Gulf of Mexico coast is currently underway (Brennan et al., 2005, 2006, 2008). 


\section{METHODS}

\section{Model Overview}

The GPIM is a single-cohort vector-based model that links potential trophic impacts of stocked individuals with estimated ecosystem productivity to inform stocking density estimation and potentially reduce the risk of overstocking and adverse ecosystem consequences (Figure 1). The model also assesses the relative impacts of different stocking scenarios (Taylor et al., 2008), such as comparisons of the outcomes of stocking at different release sizes, release species, and release systems. The model is designed to use parameters that are commonly available from literature or species stock assessments or that can be obtained relatively easily from empirical measurements (Figure 1). The model limits stocking density such that trophic impacts on average do not exceed a specified proportion of total productivity at the trophic level being preyed upon (specified as the trophic impact factor).

\section{Base Model Structure}

Fish growth is described by a standard von Bertalanffy growth model and a length-weight relationship:

$$
\begin{aligned}
L_{t} & =L_{\infty}\left(1-e^{-k\left(t-t_{0}\right)}\right), \\
W_{t} & =a \cdot L_{t}^{b},
\end{aligned}
$$

where $L_{t}$ and $W_{t}$ reflect length and weight as a function of time, respectively, $k$ is the von Bertalanffy growth rate coefficient, $L_{\infty}$ is the asymptotic length, $t_{0}$ is the theoretical age at which $L=$
$0, a$ and $b$ are the weight coefficient and exponent, respectively, and $t$ is the post-release time step during the model period. These relationships are carried through the model as vectors of length and weight values for the period between age-since-stocking $\left(t_{\text {stock }}\right)$ and the age at the conclusion of the model period $\left(t_{\max }\right)$.

Consumption-per-unit-biomass $(Q / B)$ can change with fish length or weight due to greater foraging efficiency, different foraging strategy, or improved allocation and availability of energetic resources. The caudal aspect ratio $A$ generalizes the bioenergetic considerations in the Palomares and Pauly (1998) $Q / B$ model, and it is expressed as a function of fish size rather than as a single value to account for the scaling of metabolism and other associated factors previously mentioned. The caudal aspect ratio is calculated as a function of changing caudal fin height $(h)$ and lateral surface area of the caudal fin $(S A)$ over the model period, according to the following equation (Pauly, 1989):

$$
A_{t}=\frac{h_{t}^{2}}{S A_{t}}
$$

Daily consumption in terms of biomass consumed per gram of consumer $\left(C_{t}, \mathrm{~g} \mathrm{~g}^{-1} \mathrm{~d}^{-1}\right)$ is calculated using a generalized predictor of consumption per unit biomass (Palomares and Pauly, 1998):

$$
C_{t}=\frac{10^{\left(7.964-0.204 \cdot \log W_{\infty}-1.965 \cdot T^{\prime}+0.083 \cdot A_{t}+0.532 \cdot h+0.398 \cdot d\right)}}{365},
$$

where $h$ and $d$ are logical values; $h=1$ and $d=0$ if the species is a herbivore, $h=0$ and $d=1$ if the species is a detritivore, and $h=0$ and $d=0$ if the species is a carnivore; and $W_{\infty}$ is the asymptotic weight. $T^{\prime}$ is the temperature of the water body $(T)$,

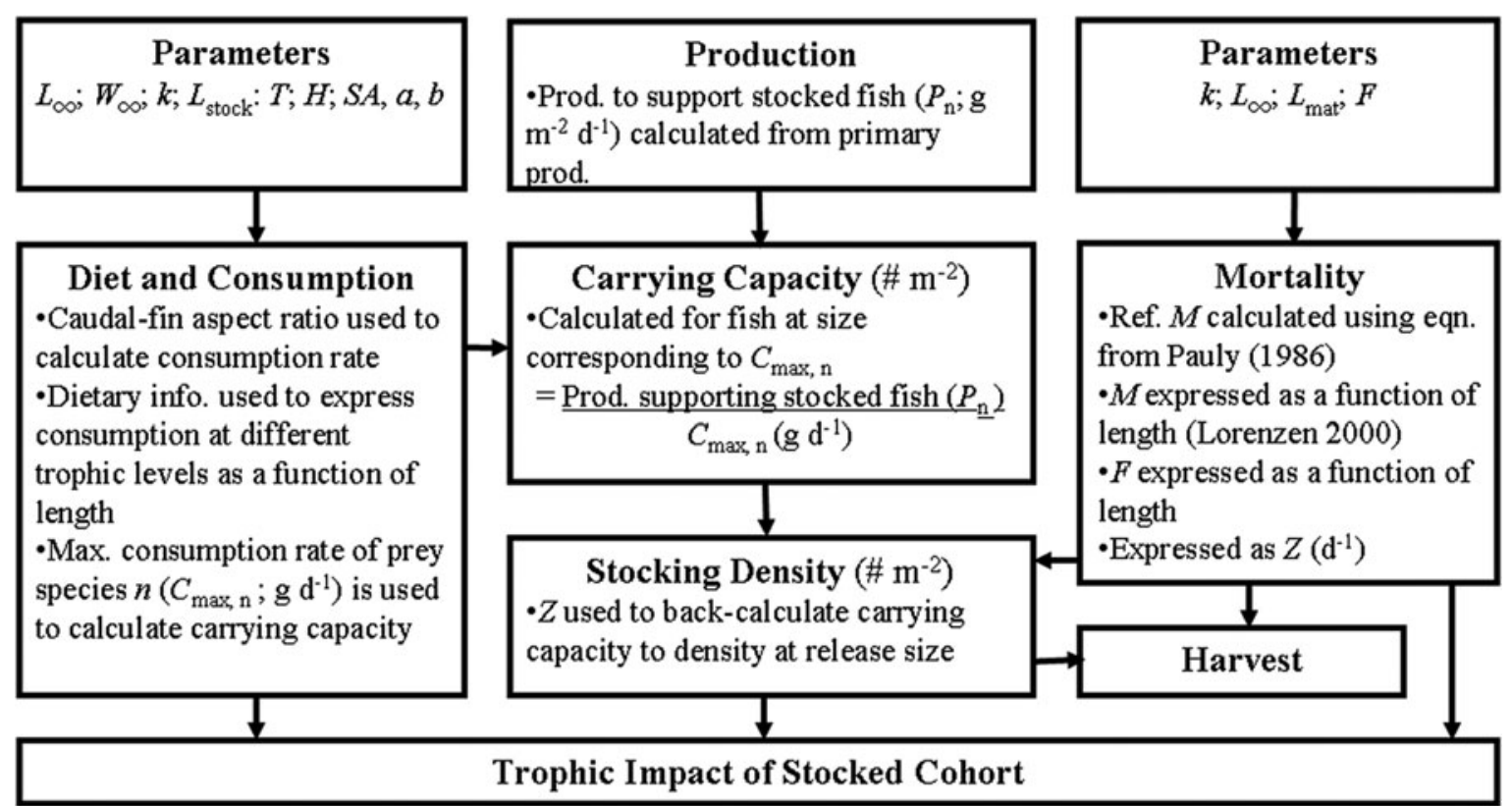

Figure 1 Conceptual layout of GPIM indicating major parameter inputs, main outputs, and information flow through the model. 
expressed in Kelvin units using the formula

$$
T^{\prime}=1000 \cdot(T+273.15)^{-1} \text {. }
$$

The model requires empirical information on the proportion of major prey items in the diet and how this varies with length or age. The model is designed such that dietary relationships should be grouped by trophic similarity. For example, if diet moves from primarily herbivorous fish prey to piscivorous fish prey, these data clearly represent an ontogenetic transition between different trophic groups. The trophic group concept allows the model to produce instantaneous estimates of production at specific trophic levels. These dietary relationships are provided for $n$ trophic groups that are important throughout the model period, and the consumption relationship is partitioned into trophic groups according to

$$
C_{t, n}=W_{t} \cdot C_{t} \cdot D_{t, n},
$$

where $C_{t, n}\left(\mathrm{~g} \mathrm{~d}^{-1}\right)$ is the modeled consumption of a single consumer fish on trophic group $n$ throughout the model period, and $D_{t, n}$ is the proportion of trophic group $n$ in the diet (which may vary throughout the model period, as described above; Taylor and Suthers, 2008). The consumption maxima that occur during the model period are evaluated by the model for $n$ trophic levels and are used to define the maximum instantaneous consumption rate of a single fish on each trophic group and the factor determining the theoretical carrying capacity $\left(C_{n, \max }\right.$; Taylor and Suthers, 2008).

The production $\left(P_{n}\right)$ available to support stocked fish is calculated for each trophic group $n$ at the corresponding trophic level using the generalized equation (Pauly and Christensen, 1995)

$$
P_{n}=P a_{n}\left(A \cdot P_{1} \cdot T E^{T L_{n}-1}\right),
$$

where $P a_{n}$ is the target trophic impact factor (the proportion of production allocated to support stocked fish), $P_{1}$ is the wetweight primary productivity in the area to be stocked, $T L_{n}$ is the estimated trophic level of trophic group $n, T E$ is the trophic transfer efficiency within the system to be stocked, and $A$ is the area of key habitat $\left(\mathrm{m}^{2}\right)$ likely to be used by stocked fish within the model period, which should include at least the foraging arena of the species (Walters and Juanes, 1993; Walters and Martell, 2004).

The parameter $P a_{n}$ accounts for the target trophic impact by apportioning the total productivity at each trophic level. The trophic impact factor refers to the upper ceiling of productivity at any particular trophic level that is available to support stocked fish, and the model will simulate trophic limits to stocking density by matching the maximum consumption rate of an individual fish at a particular trophic level (i.e., $C_{n, \max }$ ) to the amount of productivity assigned to support the stocked cohort (i.e., $P_{n}$ ). For example, if an acceptable trophic impact factor was $5 \%$ of productivity at trophic level $n, P a_{n}$ would be specified as 0.05 , and $P_{n}$ would provide an estimate of upper productivity ceiling at trophic level $n$, which is assigned to support the cohort of stocked fish. Thus, the total consumption rate of the cohort, on average, should not exceed this upper limit of productivity. Different values of $P a_{n}$ can be specified for each individual trophic level. Specification of $P a_{n}$ for any trophic level may depend on the structure of the ecosystem, the objectives of the release program, and/or the magnitude of perceived or actual recruitment limitation. Trophic impact, productivity, and consumption rates for each trophic group $n$ are used to estimate the carrying capacity for stocked fish of the given habitat for the size at which $C_{n \text {, max }}$ values occur using the following:

$$
C C_{n}=\frac{P_{n}}{C_{n, \max }} .
$$

Where estimates of natural mortality obtained from empirical data are not available for the species, natural mortality is calculated as a function of $L_{\infty}, K$, and $T$ using the generalized equation of Pauly (1980):

$$
M=10^{-0.0066-0.279 \cdot \log L_{\infty}+0.6543 \cdot \log k+0.4634 \cdot \log T} .
$$

While this represents the default equation for natural mortality where empirical information is not available, it can be incorporated with other estimators of natural mortality (e.g., Hoenig, 1983; Ralston, 1987) using established methods (Hall et al., 2004) for inclusion in the model.

Several previous studies provide evidence for an allometric relationship between natural mortality and body weight (see Lorenzen, 1996, and references therein). Accounting for this relationship is particularly important in stocked fisheries, where release size is of key interest. Lorenzen (2006) proposed a relationship where natural mortality is inversely proportional to length, which allows natural mortality to be expressed as a function of length at time-after-release $\left(M_{t}\right)$ :

$$
M_{t}=M_{r}\left(\frac{L_{r}}{L_{t}}\right),
$$

where $M_{r}$ is the mortality rate at reference length $L_{r}$. Mortality rates estimated for recruited fish or those predicted by the Pauly (1980) equation typically correspond to the mortality rate at the size at maturation; hence, $M_{r}$ was set equal to the estimated value and $L_{r}$ to equal $L_{\text {mat }}$ (Lorenzen, 2011).

Fishing mortality $\left(F_{t}\right)$ is expressed as the product of the fishing mortality $(F)$ for the fully selected length groups and a length-based logistic selectivity curve:

$$
F_{t}=F \cdot \frac{e^{\left(a+b \cdot L_{t}\right)}}{1+e^{\left(a+b \cdot L_{t}\right)}},
$$

where $a$ and $b$ are constants. The above calculation of fishing mortality is dependent on the type of gear used, and alternative selectivity formulas may be substituted if appropriate. For fish species targeted by anglers where selectivity is not well known, the length at which fish recruit to the fishery (usually the minimum length that can be legally retained by the angler) may be substituted for $L_{50}$ in the above equation, which would then provide an approximation of the change in fishing mortality with 
size- and time-post-release. The total daily mortality rate $Z_{t}$ is expressed as the sum of $M_{t}$ and $F_{t}$ :

$$
Z_{t}=\frac{M_{t}+F_{t}}{365}
$$

The instantaneous daily mortality estimates $\left(Z_{t}\right)$ are used to back-calculate stocking density for each trophic group $n$ at the specified length-at-stocking $\left(L_{\text {stock }}\right)$ for each carrying capacity estimate using the equation

$$
S D_{n}=C C_{n} \cdot e^{\sum_{t=t_{\text {stock }}}^{t_{c \max n}} Z_{t}}
$$

where $C C_{n}$ is the carrying capacity calculated for trophic group $n, t_{\text {stock }}$ is the age-at-stocking, and $t_{c \max n}$ is the corresponding time-since-stocking $(d)$ at which $C_{\max , n}$ occurred. A global stocking density estimate is produced by averaging the values of $S D$ obtained for each trophic group.

The model also calculates the expected harvest and total impact on the trophic groups over the model period, for the estimated stocking density. The total impact reflects the total biomass consumed by the stocked cohort over the model period and is useful for considering the relative trophic impact per unit yield among release scenarios. The number of fish remaining after time-since-stocking $t(d)$ is calculated for the model period $\left(t_{\text {stock }} \leq t \leq t_{\max }\right)$ as

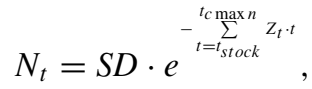

and cumulative biomass harvested $(H)$ is calculated as a function of time-since-stocking for the model period $\left(t_{\text {stock }} \leq t \leq t_{\max }\right)$ using a modification of the Baranov catch equation:

$$
H=\sum_{t=t_{\text {stock }}}^{t_{\max }} \frac{F_{t}}{Z_{t}} \cdot N_{t} \cdot\left(1-e^{-Z_{t}}\right) \cdot W_{t} .
$$

The model then integrates abundance and biomass estimates over the period $t_{\text {stock }}$ to $t_{\max }$ to determine the total trophic impact (TI) on each trophic group $n$ using the equation

$$
T I_{n}=\sum_{k=t_{\text {stock }}}^{t_{\max }} N_{t} \cdot C_{t, n},
$$

where $N_{t}$ and $C_{t, n}$ are the number of fish remaining for each daily time step and daily consumption on trophic group $n$, respectively. Total trophic impact is determined by summing the impacts on $n$ trophic groups.

\section{Sensitivity Analysis}

A MATLAB (MathWorks, Natick, MA, USA) script representing the above model was used for all simulations. A sensitivity analysis was undertaken on key parameters within the model to determine the relative effect of these parameters in driving model predictions. A parameter set for mulloway (Argyrosomus japonicus, see description below) was used for these simulations (Table 1). Monte Carlo simulations were used to produce unique parameter sets for each model run, comprising random combinations of either the estimate for each parameter or the estimate $\pm 10 \%$. Monte Carlo simulations continued until the variance in stocking density estimates stabilized.

Parameters and outputs were standardized such that parameter coefficients directly indicated the first-order effects, and thus the relative importance of the corresponding parameters, following the approach of Kleijen (1997). The standardization

\begin{tabular}{|c|c|c|c|c|c|}
\hline Parameter & Name & $-10 \%$ & Value & $+10 \%$ & Supporting sources \\
\hline$k\left(L_{\infty}\right)^{a}$ & $\begin{array}{l}\text { Growth growth rate coefficient } \\
\quad \text { (asymptotic length) }\end{array}$ & $0.23(134)$ & $0.26(122)$ & $0.29(110)$ & Silberschneider and Gray (2005) \\
\hline$T$ & Temperature & 15.7 & 17.4 & 19.4 & $\begin{array}{l}\text { Measured from field data (Georges River, } \\
\text { Sydney, Australia) }\end{array}$ \\
\hline$F$ & Fishing mortality & 0.495 & 0.55 & 0.605 & Silberschneider and Gray (2005) \\
\hline$P_{1}$ & Primary productivity & 1.24 & 1.38 & 1.52 & $\begin{array}{l}\text { Estimated using the simple estuarine } \\
\text { response model (SERM; Baird et al., 2003) }\end{array}$ \\
\hline$T E$ & Trophic transfer efficiency & 0.09 & 0.10 & 0.11 & Pauly and Christensen (1995) \\
\hline$T L_{1}$ & Trophic level of trophic group 1 & 2.18 & 2.40 & 2.67 & \\
\hline$T L_{2}$ & Trophic level of trophic group 1 & 2.36 & 2.60 & 2.88 & Estimated using data in Taylor et al. (2006a) \\
\hline$T L_{3}$ & Trophic level of trophic group 1 & 2.72 & 3.00 & 3.33 & \\
\hline
\end{tabular}
process involved first determining the spread $\left(a_{h}\right)$ and mean $\left(b_{h}\right)$ of possible values each parameter $h$ could take:

$$
\begin{aligned}
a_{h} & =\frac{h_{\max }-h_{\min }}{2}, \\
b_{h} & =\frac{h_{\max }+h_{\min }}{2},
\end{aligned}
$$

Table 1 Mean (and variations on the mean) for mulloway Argyrosomus japonicus used in sensitivity analysis simulations

${ }^{a}$ Due to the covariance structure between $K$ and $L_{\infty}$, these parameters were set as inverse covariates to reduce variance inflation in the sensitivity analysis. 
and then calculating a standardized value of parameter $h$ in the parameter set $i\left(x_{i h}\right)$ :

$$
x_{i h}=\frac{z_{i h}-b_{h}}{a_{h}},
$$

where $z_{i h}$ is the original non-standardized value of parameter $h$.

Best-fit equations were developed using step-wise regression analysis of parameter combinations against resultant model outputs (Kleijnen, 1997), and competing best-fit equations were evaluated using Akaike information criteria in the open-source statistical package $R$ v. 2.6.1 (Ihaka and Gentleman, 1996). The resulting regression equation provided approximations of the input/output behavior of the simulation model and parameter coefficients that directly indicated the relative importance of parameters in determining stocking density.

\section{Simulation Structure}

To account for uncertainty in parameter estimation, the parameters that were identified as significant drivers of the model in the sensitivity analysis were specified in the model as probability distributions. Probability distributions were developed on the basis of mean and error variance estimates from various published sources (Table 2). As $K$ and $L_{\infty}$ are correlated (Pilling et al., 2002), these parameters were specified as a multivariate probability density function informed by the variancecovariance structure between $K$ and $L_{\infty}$ in a non-linear fit of the von Bertalanffy growth model to length-age data for each species.

The model was structured as a Monte Carlo analysis of uncertainty (MCAoU), a common approach to assessing risk in ecological systems (Bartell et al., 1992). Each model simulation sampled a value from each parameter's probability distribution until variance in stocking density stabilized, thus producing a probability distribution of stocking density estimates, which corresponded to the specified trophic impact factor. The model also used the relationships described above to estimate the probability distribution for trophic impact and harvest associated with the specified parameter set.

\section{Case Studies to Demonstrate the Application of GPIM}

The GPIM was applied to two predatory fish species (Argyrosomus japonicas and Centropomus undecimalis) to demonstrate the generality of the model structure. These species were chosen because they occupy a similar trophic position but differ in growth, fishing impact, and ecosystem, and there were sufficient existing data to parameterize the model. Simulations for mulloway were performed using temperature measurements and primary productivity estimates in the Georges River, Sydney, Australia, an estuary that has previously been stocked with mulloway (Taylor et al., 2009). Average annual temperatures and associated variance were measured in the river using temperature loggers (Hobo Pendant) from November 2007 to November 2008. A depth-integrated primary productivity estimate and associated variance was estimated for the Georges River using the simple estuarine response model (SERM) described in Baird et al. (2003). Simulations for snook were performed using temperature and primary productivity estimates in the North Creek Estuary (on the basis of previous measurements in the same area, Pomeroy, 1960; Bucolo et al., 2008), Sarasota, Florida, an

Table 2 Parameter values for mulloway Argyrosomus japonicus and snook Centropomus undecimalis used in GPIM simulations

\begin{tabular}{|c|c|c|c|c|}
\hline \multirow[b]{2}{*}{ Parameter } & \multicolumn{2}{|c|}{ Argyrosomus japonicus } & \multicolumn{2}{|c|}{ Centropomus undecimalis } \\
\hline & Estimate & Supporting sources & Estimate & Supporting sources \\
\hline$h$ & 0 & | Pauly (1989) & 0 & Pauly (1989) \\
\hline$d$ & 0 & & 0 & \\
\hline$a$ & 0.00001679 & Silberschneider and Gray (2005) & 0.0000044014 & \\
\hline$b$ & 2.869 & & 3.1117 & Muller and Taylor (2006) \\
\hline$t_{0}$ & -0.0552 & & -0.04 & \\
\hline$L_{\text {stock }}(\mathrm{cm})$ & 10 & Taylor et al. (2009) & 8.1 & Brennan et al. (2008) \\
\hline$L_{\text {mat }}(\mathrm{cm})$ & 51 & Silberschneider et al. (2009) & 20 & Muller and Taylor (2006) \\
\hline$k$ & $N\left(0.27,4.58 \mathrm{e}^{-5}\right)$ & Estimated from length-age data for & $N\left(0.35,8.43 \mathrm{e}^{-4}\right)$ & Estimated from length-age data for \\
\hline $\begin{array}{l}L_{\infty} \\
T\end{array}$ & $\begin{array}{l}N(122.9,2.6) \\
N(17.9,3.9)\end{array}$ & $\begin{array}{l}\text { mulloway stock in NSW } \\
\text { Measured from field data (Georges } \\
\text { River, Sydney, Australia) }\end{array}$ & $\begin{array}{l}N(75.1,12.9) \\
N(22.5,2.3)\end{array}$ & $\begin{array}{l}\text { snook stocked in Sarasota, } \text { FL }^{b} \\
\text { Measured from field data (North Creek, } \\
\text { Sarasota, FL, USA) }\end{array}$ \\
\hline$F$ & $N(0.5,0.1)$ & $\begin{array}{l}\text { Estimated from Silberschneider and } \\
\text { Gray (2005) }\end{array}$ & $N(0.6,0.1)$ & $\begin{array}{l}\text { Estimated from Muller and Taylor } \\
\text { (2005) }\end{array}$ \\
\hline$P_{1}$ & $N(1.38,0.36)$ & SERM (Baird et al., 2003) & $N(1.20,0.37)$ & $\begin{array}{l}\text { Estimated from Pomeroy (1960) and } \\
\text { Bucolo et al. (2008) }\end{array}$ \\
\hline$T E$ & $N(0.10,0.06)$ & Pauly and Christensen (1995) & $N(0.10,0.06)$ & Pauly and Christensen (1995) \\
\hline$T L_{1}$ & $N(2.4,0.2)$ & () & $N(2.2,0.2)$ & ) \\
\hline$T L_{2}$ & $N(2.6,0.3)$ & Estimated using data in Taylor et al. & $N(2.3,0.2)$ & Estimated using data in Blewett et al. \\
\hline$T L_{3}$ & $N(3.0,0.3)$ & $(2006 a)$ & $N(2.5,0.3)$ & $(2006)$ \\
\hline
\end{tabular}

${ }^{a}$ Data made available from NSW Department of Primary Industries length-age databases.

${ }^{b}$ Data made available from snook stock-recapture databases. 
estuary in which several pilot snook releases have taken place (Brennan et al., 2005, 2006, 2008).

The parameters and probability distributions for each of these species are presented in Table 2 . For case study simulations, $A$ was held constant at $10,000 \mathrm{~m}^{2}$ to provide a stocking density estimate for 1 hectare of key habitat for each species. Snook recruit to the fishery at a much older age than mulloway, and for this reason, $t_{\max }$ (i.e., age at which fish are well recruited to the fishery; conclusion of model period) was set at 1,642 days (approximately 4.5 years) for mulloway and 2,190 days (approximately 6 years) for snook. The results of the simulations are thus specific for the species and geographic area and the fishery that was used to inform the parameter estimates shown in Table 2.

\section{RESULTS}

\section{Sensitivity Analysis}

The best model produced from the multiple regression and model selection routines included all the key parameters provided to the model (Figure 2 ) and explained $72 \%$ of the variation in the estimated stocking density $(F=9,815 ; p \ll 0.001)$. Results of the sensitivity analysis (Figure 2) indicate that $k$ (von Bertalanffy growth coefficient) had the largest relative positive correlation with stocking density. Fishing mortality $(F)$ and the productivity parameters $P_{1}$ and $T E$ also had lower relative positive correlations with stocking density (Figure 2). Both $T$ and $T L_{n}$ correlated negatively with stocking density. The lowest trophic level $\left(T L_{1}\right)$ was the most influential trophic level on the model results when compared with a moderate influence of the intermediate level $\left(T L_{2}\right)$ and the lowest influence from the high trophic level ( $T L_{3}$, Figure 2).

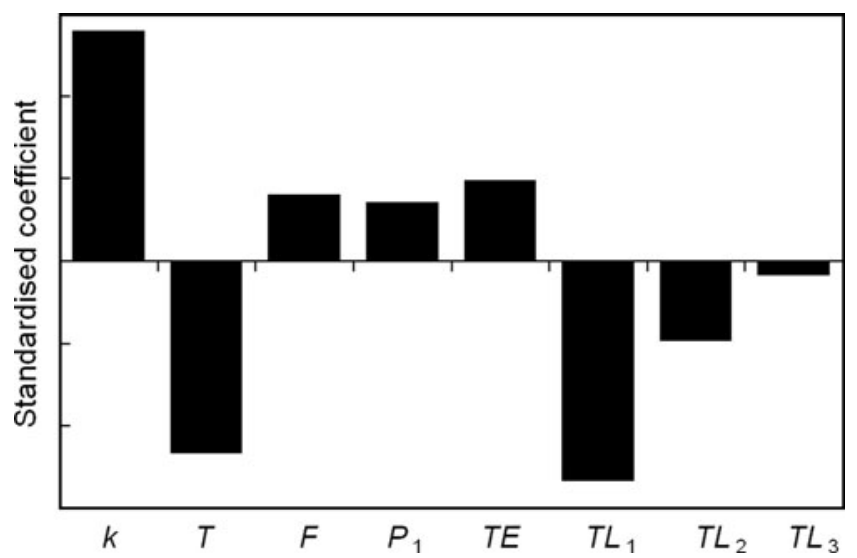

Figure 2 Results of sensitivity analysis for GPIM showing relative impacts of key parameters on model simulations for mulloway $(k$, von Bertelanffy growth coefficient; $T$, mean environmental temperature; $F$, fishing mortality; $P_{1}$, primary productivity; $T E$, trophic transfer efficiency; $T L_{1}, T L_{2}$, and $T L_{3}$, tropic levels of three trophic groups). Magnitude of each measurement directly reflects the relative importance of that parameter in driving stocking density.

\section{Case Study Simulations}

On the basis of the parameter set provided, the optimal simulated stocking density for mulloway within the Georges River is $\sim 50$ fish ha $^{-1}$ at a release size of 100-mm TL (Figure 3A). The mean potential harvest and impact (over the model period) associated with this stocking rate are $\sim 11 \mathrm{~kg} \mathrm{ha}^{-1}$ (Figure 3B) and $\sim 320 \mathrm{~kg} \mathrm{ha}^{-1}$ (Figure 3C), respectively, over $\sim 4.5$ years. The harvest is also expressed as a mean yield of $\sim 0.24 \mathrm{~kg}$ (Figure 3D) harvest per fish stocked in the scenario.

For snook, the optimal stocking density estimated on the basis of the parameter set provided for North Creek is $\sim 660$ fish $\mathrm{ha}^{-1}$ at a release size of $80 \mathrm{~mm}$ standard length (SL, Figure 4A). The mean potential harvest and impact (over the model period) associated with this stocking rate is $\sim 84 \mathrm{~kg} \mathrm{ha}^{-1}$ (Figure $4 \mathrm{~B}$ ) and $\sim 4,425 \mathrm{~kg} \mathrm{ha}^{-1}$ (Figure 4C), respectively. A mean yield of $\sim 0.13 \mathrm{~kg}$ (Figure 4D) catch per fish stocked is estimated for snook in this scenario. Note that these outputs consider only a single stocking event and do not consider the implications of stocking multiple cohorts in successive year.

\section{DISCUSSION}

The GPIM is the first generalized trophic model explicitly aimed at providing estimates of limits to stocking density for stock enhancement or sea ranching scenarios. The GPIM is essentially a synthesis of generalized predictive models that are structured in such a fashion as to provide estimates of parameters of principal interest to managers or scientists involved in fish releases. Taylor and Suthers (2008) first presented the PIM, which was designed to estimate release densities for mulloway. The GPIM developed in the current study draws on the concepts of the original PIM with important improvements. The generalized estimator of consumption (Palomares and Pauly, 1998) remains at the center of the GPIM, and this forms the basis of the estimation of carrying capacity, as proposed in Taylor and Suthers (2008; Figure 1).

The GPIM makes several key advances on the PIM and addresses several key limitations outlined in Taylor and Suthers (2008). The first key limitation of the PIM was the estimation of prey productivity on which stocking density is based. Previously, this relied on empirical measurements or species-specific estimates of prey productivity. The GPIM includes a conventional generalized approach to estimating productivity by including a general trophic productivity model (Figure 1), which relates consumption rates on the specific trophic levels on which the released species feeds to the productivity at these trophic levels (Pauly and Christensen, 1995). This allows the model to account for more generalist feeding strategies, which are often observed in fish populations (e.g., Barnes et al., 2011; Smith et al., 2011). The second major enhancement in GPIM is that it draws on recent publications to include mortality as size-based functions, thus taking into account the relatively high rates of 

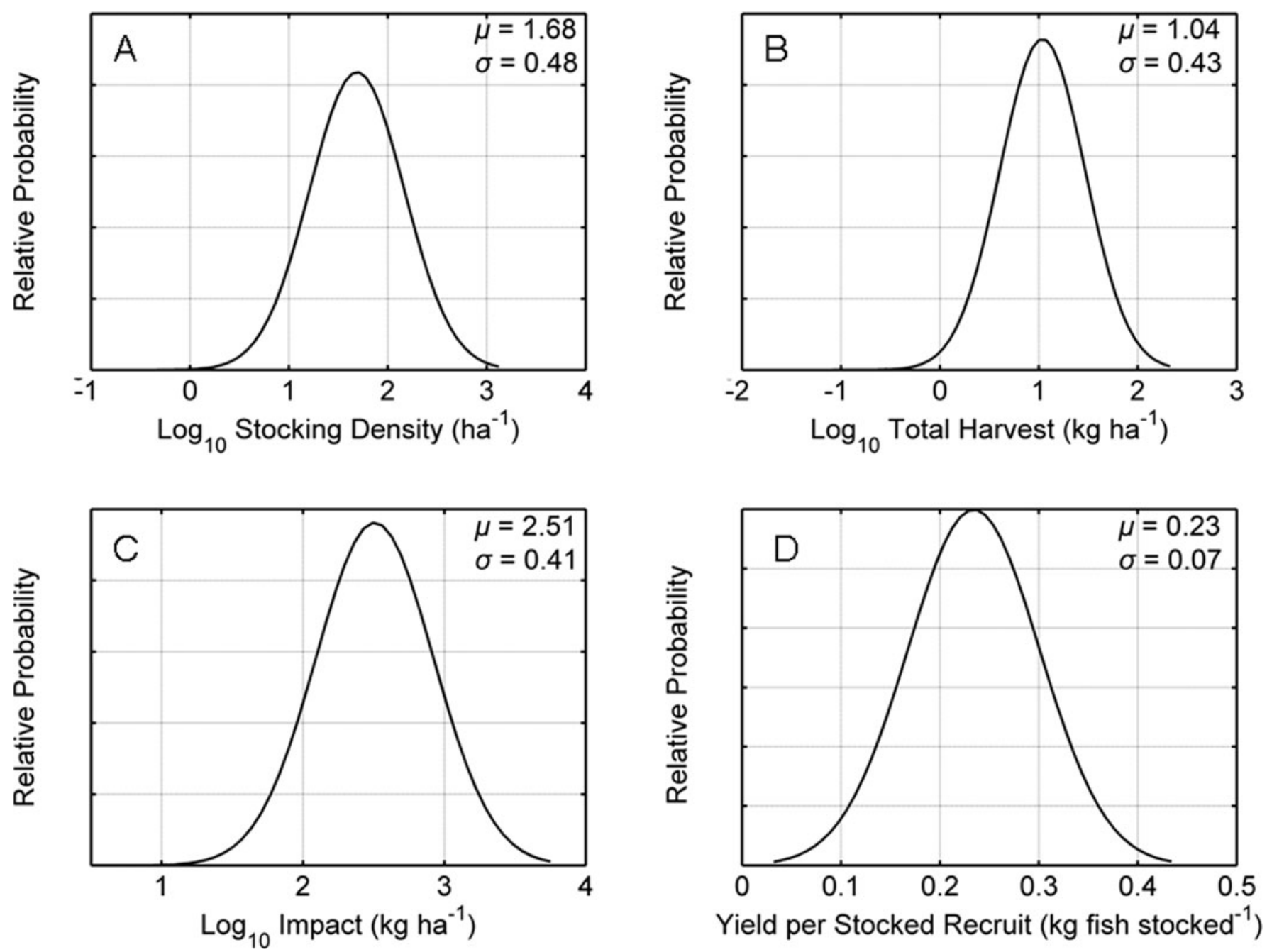

Figure 3 GPIM simulation outputs for mulloway Argyrosomus japnoicus released into Georges River, New South Wales, Australia. Relative probability is shown for the four key model outputs: (A) potential stocking density, (B) potential harvest, (C) potential trophic impact, and (D) potential yield per stocked recruit.

natural mortality, which may be experienced by stocked fish in the early stages post-release (e.g., Lorenzen, 2000, 2006). Third, the PIM failed to take account of uncertainty in model parameters. This has been addressed in the GPIM, as key parameters driving model simulations revealed by the sensitivity analysis are now provided as probability distributions, and uncertainty is incorporated through an MCAoU.

Munro and Bell (1997) first suggested that ECOPATH models could be useful for estimating the effects of enhancing recruitment of specific components of an ecosystem, and recent versions of the model allow the incorporation of hatchery stocking into model scenarios (Christensen et al., 2005). There is, however, a paucity of examples in the scientific literature that have employed this model in the context of stock enhancement, although few examples do exist in the gray literature (Christensen, 1994; Rogers and Allen, 2008). This may be because the time and cost required for parameterization and development of a full ecosystem model for the receiving sys- tem, such as ECOPATH, may be prohibitive at the early stages of stock enhancement or sea-ranching projects. Many of the concepts that underpin the GPIM are drawn from ECOPATH, particularly the trophic level and mass balance concepts and the estimation of consumption (Christensen and Pauly, 1992). Thus, the reduced data requirements for the GPIM allow stocking scenarios to be assessed according to these concepts but without the development of a full ecosystem model, which provides a considerable advantage for developing stocking research programs.

\section{Factors Driving Model Estimations}

Results of the sensitivity analysis revealed that growth and temperature are important variables driving the estimation of trophic limits to stocking density in the GPIM. Temperature and growth are key components of the generalized estimators 

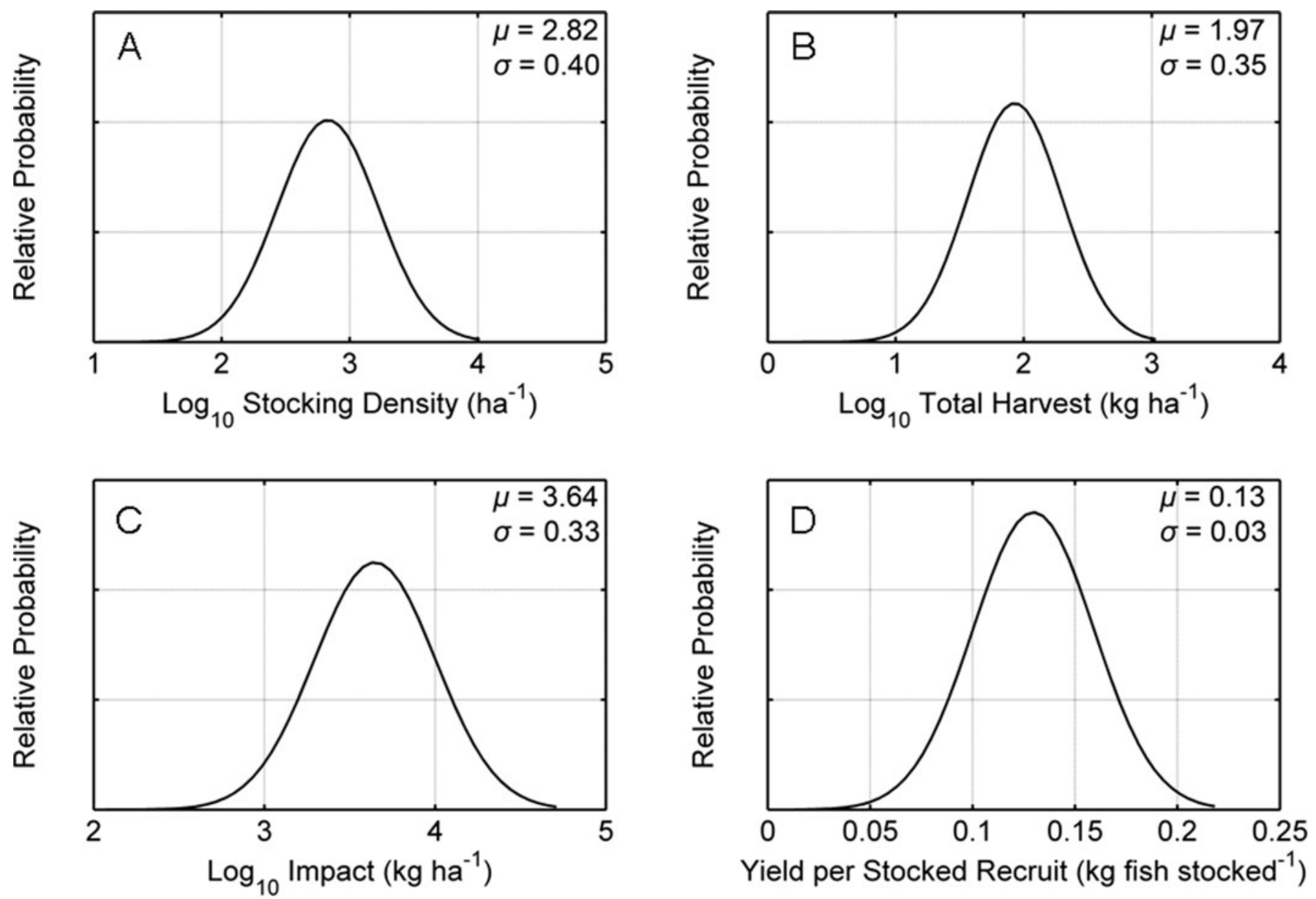

Figure 4 GPIM simulation outputs for snook Centropomus undecimalis released into North Creek, Florida, USA. Relative probability is shown for the four key model outputs: (A) potential stocking density, (B) potential harvest, (C) potential trophic impact, and (D) potential yield per stocked recruit.

of mortality (Pauly, 1980) and consumption (Palomares and Pauly, 1998), and the relative relationship of temperature and growth with stocking density can be explained by considering both metabolic theory and mortality during the model period, respectively.

Temperature is negatively related to stocking density through the generalized estimator of consumption per unit biomass. Consumption has a negative relationship with $T^{\prime}$, which is an inverse measure of temperature (Palomares and Pauly, 1998). Consequently, temperature has an indirect positive relationship with consumption, as individual rates of metabolism are positively temperature dependent (Brown et al., 2004). Thus, higher relative consumption rates lower the number of individuals that the system can support within the specified threshold of trophic impact. The positive correlation between growth coefficient $k$ and stocking density arises due to the cumulative mortality experienced by the cohort during the model period. A higher $k$ and associated faster growth means that the cohort recruits to the fishery at an earlier point in the model period. This means that fish are exposed to fishing mortality over a larger proportion of the model period (which also contributes to a greater harvest) and, thus, experience greater overall mortality during the model period. The elevated loss of fish from the system during the model period means that a higher stocking density can be supported to fully utilize the trophic resources allocated to support the stocked cohort.

Unsurprisingly, parameters relating to trophic productivity $\left(P_{1}, T E\right)$ positively relate to stocking density. Greater primary productivity $\left(P_{1}\right)$ means a greater mass of carbon is entering the system, thus increasing the relative carrying capacity and stocking density. A greater trophic efficiency (TE) equates to a more efficient passage of carbon between trophic levels, so a larger portion of the biomass synthesized by primary producers is conveyed to the higher trophic levels on which stocked fish are preying. The negative relationship between trophic level $\left(T L_{n}\right)$ and stocking density reflects differences in the relative magnitude of production, which is conveyed to these higher trophic levels. The generalized estimator of productivity (Pauly and Christensen, 1995) shows that the available production decreases with an increasing trophic level, thus producing a 
negative relationship between stocking density and the trophic level of a trophic group appearing in the diet.

\section{Constraining Trophic Impact}

The GPIM is intended primarily as a risk reduction tool to lower the chance of the negative effects on the stocked species' prey, which may occur as a result of overstocking. Overstocking occurs where the capacity of the receiving system to support recruits is exceeded and can have effects at the population or community level. For example, overstocking grass carp (Ctenopharyngodon idella) in Lake Erhai (China) had adverse effects at the community level through suppressed growth of aquatic macrophytes (Li, 1999; Liu et al., 2008). In addition, Tatara et al. (2011) found that while the stocking of hatcheryreared steelhead parr (Oncorhynchus mykiss) into experimental streams led to an increase in the composite (hatchery-reared and natural) population, the emigration of natural steelhead parr led to an overall decrease in the abundance of natural recruits. Evidence of displacement arising from overstocking is rare in marine systems, potentially due to the complex experimental framework required to detect population and community changes in manipulated ecosystems (some good examples can be found in Leber et al., 1995; Kellison et al., 2003; Brennan et al., 2008; Eggleston et al., 2008). It should be noted, though, that if fish survive to reproduce, density dependence may arise, such as increased mortality or displacement in subsequent generations.

The trophic impact factor, as defined in the context of this model, is a new concept in stock enhancement, which partially deals with the potential for impacts on food resources and other organisms. Recruitment limitation is a key assumption underlying releases of fish into open marine systems (Munro and Bell, 1997; Taylor et al., 2005; Lorenzen et al., 2010); however, it is rarely quantified and used as a basis for release densities, despite tools being available that explicitly allow this (e.g., Medley and Lorenzen, 2006). In the GPIM, the trophic impact factor is largely a subjective parameter, but it is one that can be based on general knowledge of the receiving system and natural stock and allows the risk of adverse competitive effects and resultant displacement or density-dependent effects to be indirectly taken into account. The simplicity of the parameter and its inclusion in the GPIM lies in the constraint of stocking density within a designated acceptable level of trophic impact and evaluation of the associated outcomes (such as potential harvest). Alternatively, the GPIM also allows stocking densities, trophic impacts, and potential harvests to be compared among a range of allowable trophic impact levels. While there is still some potential risk of overstocking when using this approach (for example, if the estimated trophic impact factor is too high for a particular system), applying the GPIM approach provides a useful, speciesand system-specific range of stocking density estimates with which to commence pilot releases. This provides a starting point for empirical evaluation of the success and effects of stocking, building on the techniques suggested previously in this section.

\section{Application of the Model Across Species}

The current study presents the application of the GPIM to two carnivorous teleost species; however, there are key features of the model that facilitate its application to a diverse range of other marine species, including herbivorous and detritovorous fish and invertebrates. Adapting the model to herbivorous or detritivorous fishes is achieved through manipulating the binary operators $h$ and $d$ in the generalized estimator of consumption (see Palomares and Pauly, 1998). Similarly, the model can be converted for use with invertebrates by including an estimate of gross growth efficiency (e.g., Wolff and Cerda, 1992) in place of the generalized estimator of consumption, which will account for the forage resources required to sustain a specific growth rate.

While the model simulations presented here are specific to the respective systems, fisheries and species for which the parameters are estimated, factors that contribute to the differences observed in model estimates between the two species are worth discussing. First, snook have a higher recommended stocking density than mulloway, which is a combination of higher primary productivity in Florida, the fact that snook feed at a lower trophic level than mulloway, and a longer model period over which fish experience mortality (6 years compared with 4.5 years). In addition, as previously described, the faster growth of snook in Florida will also act to increase stocking density estimates. The higher trophic impact estimates observed for snook in Florida arise from higher stocking density and the longer duration of the model period $(\sim 4.5$ years for mulloway versus $\sim 6$ years for snook) during which trophic impacts accumulate. Overall, the total harvest is greater for snook in Florida as a result of greater fishing mortality, greater stocking density, and a longer model period. In contrast, the yield per stocked recruit is slightly higher for mulloway due to a lower natural mortality.

The GPIM is also useful for evaluating the potential suitability of species of differing biological and/or fishery characteristics for a particular system by holding ecosystem characteristics constant and altering other parameters according to the particular species. Conversely, the potential outcomes for scenarios dealing with the release of a single species across different systems can be also evaluated by providing the model with speciesspecific data for each of the particular systems. In addition, the stocking densities and potential outcomes of stocking different sized cohorts of fish can also be evaluated using the GPIM, which is of relevance to evaluating the cost-to-benefit outcomes of different release scenarios.

\section{CONCLUSIONS}

In conclusion, the GPIM represents one of a range of tools useful in planning stocking programs. This approach also highlights the significance of reliable fundamental biological data on growth, mortality, and feeding ecology in planning release endeavours. The model is useful for desktop evaluation of 
different stocking strategies but does not capture all of the extrinsic processes that may act on stocked populations during and after release. Consequently, complementary approaches (such as EnhanceFish; Medley and Lorenzen, 2006) should also be employed, and model estimates should always be considered a first step in the process. EnhanceFish is based on fishery stock assessment approach and deals explicitly with density-dependence and mortality for both wild and released fish and genetic interactions. Further, the major focus of developing release programs should remain on empirically evaluating pilot-scales releases in the field (e.g., Blankenship and Leber, 1995; Leber et al., 1998; Brennan et al., 2006, 2008; Leber, 2011; Leber and Blankenship, 2012) and validating model estimates. The model provides a starting point for estimating release sizes, and the accuracy of the predictions can be validated by both experimental work and reviewing the results from trial releases. These pilot-scale releases are ideally conducted in a targeted fashion based on a solid understanding of species biology and ecosystem characteristics (e.g., Taylor et al., 2013), which will help to ensure that species requirements are met by the stocked system and improve the survival of stocked fish (Taylor et al., 2009).

\section{ACKNOWLEDGMENTS}

This project was undertaken using funding partially provided by an Australian Research Council Linkage Grant (LP0775000) with the NSW Department of Primary Industries and NSW Recreational Saltwater Fishing Trust. The authors thank those that provided unpublished data for model simulations or provided advice during model development, including J. P. Scandol and M. C. Ives. The initial stages of this work were undertaken during a scientific visit by M. D. Taylor to The Oceanic Institute (D. A. Ziemann), Hawaii, funded by the Australian Academy of Science. Please contact the corresponding author to obtain the latest version of the GPIM MATLAB code for further development or application.

\section{REFERENCES}

Baird, M., S. Walker, B. Wallace, I. Webster, and J. Parslow. The use of mechanistic descriptions of algal growth and zooplankton grazing in an estuarine eutrophication model. Estuar. Coast. Shelf. Sci., 56: 685-695 (2003).

Barnes, L., M. Leclerc, C. Gray, and J. Williamson. Dietary niche differentiation of five sympatric species of Platycephalidae. Env. Biol. Fish., 90: 429-441 (2011).

Bartell, S. M., R. H. Gardner, and R. V. O'Neill. Ecological risk estimation, Chelsea: Lewis, 252 pp. (1992).

Beddington, J. R., D. J. Agnew, and C. W. Clark. Current problems in the management of marine fisheries. Science, 316: 1713-1716 (2007).

Bell, J. D., D. M. Bartley, K. Lorenzen, and N. R. Loneragan. Restocking and stock enhancement of coastal fisheries: Potential, problems and progress. Fish.Res., 80: 1 (2006).
Bell, J. D., K. M. Leber, H. L. Blankenship, N. R. Loneragan, and R. Masuda. A new era for restocking, stock enhancement and sea ranching of coastal fisheries resources. Rev. Fish. Sci., 16: 1-9 (2008).

Blankenship, H. L., and K. M. Leber. A responsible approach to marine stock enhancement. Am. Fish. Soc. Symp., 15: 167-175 (1995).

Blewett, D. A., R. A. Hensley, and P. W. Stevens. Feeding habits of common snook, Centropomus undecimalis, in Charlotte Harbor, Florida. Gulf Caribb Res, 18: 1-13 (2006).

Brennan, N. P., M. C. Darcy, and K. M. Leber. Predator-free enclosures improve post-release survival of stocked common snook. J. Exp. Mar. Biol. Ecol., 335: 302 (2006).

Brennan, N. P., K. M. Leber, H. L. Blankenship, J. M. Ransier, and R. DeBruler Jr. An evaluation of coded wire and elastomer tag performance in juvenile common snook under field and laboratory conditions. N. Am. J. Fish. Manag., 25: 437-445 (2005).

Brennan, N. P., C. J. Walters, and K. M. Leber. Manipulations of stocking magnitude: Addressing density-dependence in a juvenile cohort of common snook (Centropomus undecimalis). Rev. Fish. Sci., 16: 215-227 (2008).

Brown, J. H., J. F. Gillooly, A. P. Allen, V. M. Savage, and G. B. West. Toward a metabolic theory of ecology. Ecology, 85: 1771-1789 (2004).

Bucolo, P., M. J. Sullivan, and P. V. Zimba. Effects of nutirent enrichment on primary production and biomass of sediment microalgae in a subtropical seagrass bed. J. Phycol., 44: 874-881 (2008).

Christensen, V. Assessing trophic impacts of fish stock enhancement. In: ICES Workshop to Evaluate the Potential for Stock Enhancement as an Approach to Fisheries Management, Charlottenlund, Denmark, May 19-24, ICES CM 1994/F:9, pp. 1-15 (1994).

Christensen, V., and D. Pauly. Ecopath II: A software for balancing steady-state ecosystem models and calculating network characteristics. Ecol Model, 61: 169-185 (1992).

Christensen, V., C. J. Walters, and D. Pauly. ECOPATH with ECOSIM: A user's guide. Vancouver: Fisheries Centre, University of British Columbia (2005).

Cook, R. M., A. Sinclair, and G. Stefansson. Potential collapse of North Sea cod stocks. Nature, 385: 521-522 (1997).

Cooney, R. T., and R. D. Brodeur. Carrying capacity and North Pacific salmon production: Stock-enhancement implications. Bull. Mar. Sci., 62: 443-464 (1998).

Doherty, P. J. Recruitment limitation is the theoretical basis for stock enhancement in marine populations, pp. 9-21. In: Stock Enhancement and Sea Ranching (Howell, B. R., E. Moksness, and T. Svåsand, Eds.). Oxford: Fishing News Books (1999).

Eggleston, D. B., E. G. Johnson, G. T. Kellison, G. R. Plaia, and C. L. Huggett. Pilot evaluation of early juvenile blue crab stock enhancement using a replicated BACI design. Rev. Fish. Sci., 16: 91-100 (2008).

Gilmore, R. G., C. J. Donohoe, and D. W. Cooke. Observations on the distribution and biology of east-central Florida populations of the common snook, Centropomus undecimalis (Bloch). Florida Scientist, 46: 313-336 (1983).

Gulland, J. A. The fish resources of the ocean. Rome: Food and Agriculture Organisation of the United Nations, 425 pp. (1970).

Hall, N. G., S. A. Hesp, and I. C. Potter. A Bayesian approach for overcoming inconsistencies in mortality estimates using, as an example, data for Acanthopagrus latus. Can. J. Fish. Aquat. Sci., 61: 1202 (2004).

Reviews in Fisheries Science vol. 21 3-4 2013 
Hilborn, R. The economic performance of marine stock enhancement projects. Bull. Mar. Sci., 62: 661-674 (1998).

Hoenig, J. M. Empirical use of longevity data to estimate mortality rates. Fish. Bull., 81: 898-903 (1983).

Ihaka, R., and R. Gentleman. R: A language for data analysis and graphics. J. Comp. Graph. Stat., 5: 299-314 (1996).

Kellison, G. T., D. B. Eggleston, J. Taylor, J. S. Burke, and J. Osborn. Pilot evaluation of summer flounder stock enhancement potential using experimental ecology. Mar. Ecol. Progr. Ser., 250: 263-278 (2003).

Kleijnen, J. P. C. Sensitivity analysis and related analyses: A review of some statistical techniques. J. Stat. Comput. Simul., 57: 111-142 (1997).

Leber, K. M. Marine fisheries enhancement: Coming of age in the new millennium, p. 20. In: Encyclopedia of Sustainability Science and Technology (Meyers, R. A., Ed.). Rueil-Malmaison, France: Springer Science (2011).

Leber, K. M., and H. L. Blankenship. How advances in tagging technology improved progress in a new science: Marine stock enhancement, pp. 3-14. In: Advances in Fish Tagging and Marking Technology (McKenzie, J. R., B. Parsons, A. C. Seitz, R. K. Kipf, and M. M. Phelps Q, Eds.). Bethesda, MD: American Fisheries Society (2012).

Leber, K. M., N. P. Brennan, and S. M. Arce. Marine enhancement with striped mullet: Are hatchery releases replenishing or displacing wild stocks? Am. Fish. Soc. Symp., 15: 376-387 (1995).

Leber, K. M., N. P. Brennan, and S. M. Arce. Recruitment patterns of cultured juvenile Pacific threadfin, Polydactylus sexfilis (Polynemidae), released along sandy marine shores in Hawaii. Bull. Mar. Sci., 62: 389-408 (1998).

Li, J. An appraisal of factors constraining the success of fish stock enhancement programmes. Fish. Manag. Ecol., 6: 161-169 (1999).

Liu, G. H., E. H. Li, L. Y. Yuan, and W. Li. Occurrence of aquatic macrophytes in a eutrophic subtropical lake in relation to toxic wastewater and fish overstocking. J. Freshw. Ecol., 23: 13-19 (2008).

Lorenzen, $\mathrm{K}$. The relationship between body weight and natural mortality in fish: A comparison of natural ecosystems and aquaculture. J. Fish. Biol., 49: 627-647 (1996).

Lorenzen, K. Allometry of natural mortality as a basis for assessing optimal release size in fish-stocking programmes. Can. J. Fish. Aquat. Sci., 57: 2374-2381 (2000).

Lorenzen, K. Population management in fisheries enhancement: Gaining key information from release experiments through use of a sizedependent mortality model. Fish. Res., 80: 19 (2006).

Lorenzen, K. Age- and size-varying natural mortality rates: Biological causes and consequences for fisheries assessment, pp. 18-21. In: Estimating Natural Mortality in Stock Assessment Applications (Brodziak, J., J. Ianelli, K. Lorenzen, and R. D. Methot Jr., Eds.). U.S. Department of Commerce, NOAA Technical Memorandum NMFS-F/SPO-119 (2011).

Lorenzen, K., K. M. Leber, and H. L. Blankenship. Responsible approach to marine stock enhancement: An update. Rev. Fish. Sci., 18: 189-210 (2010).

McMichael Jr., R. H., K. Peters, and G. R. Parsons. Early life history of the snook Centropomus undecimalis in Tampa Bay, Florida. Northeast Gulf Sci., 10: 113-125 (1989).

Medley, P. A. H., and K. Lorenzen. EnhanceFish: A decision tool for aquaculture-based fisheries enhancement. London: Imperial College (2006).
Muller, R. G., and R. G. Taylor. The 2005 stock assessment update of common snook, Centropomus undecimalis. St. Petersburg, Fish and Wildlife Research Institute, 137 pp. (2006).

Munro, J. L., and J. D. Bell. Enhancement of marine fisheries resources. Rev. Fish. Sci., 5: 185-222 (1997).

Palomares, M., and D. Pauly. Predicting food consumption of fish populations as functions of mortality, food type, morphometrics, temperature and salinity. Mar. Freshw. Res., 49: 447-453 (1998).

Pauly, D. Interrelationships between natural mortality, growth parameters and mean environmental temperature in 175 fish stocks. J. Cons. Int. Expl. Mer, 39: 175-192 (1980).

Pauly, D. Food consumption by tropical and temperate fish populations: Some generalisations. J Fish. Biol., 35(Supplement A): 11-20 (1989).

Pauly, D., and V. Christensen. Primary production to sustain global fisheries. Nature, 374: 255-257 (1995).

Pauly, D., V. Christensen, S. Guénette, T. J. Pitcher, U. R. Sumaila, C. J. Walters, R. Watson, and D. C. Zeller. Towards sustainability in world fisheries. Nature, 418: 689-695 (2002).

Peters, K. M., R. E. Matheson, and R. C. Taylor. Reproduction and early life history of common snook, Centropomus undecimalis (Bloch), in Florida. Bull. Mar. Sci., 62: 509-529 (1998).

Pilling, G. M., G. P. Kirkwood, and S. G. Walker. An improved method for estimating individual growth variability in fish, and the correlation between von Bertalanffy growth parameters. Can. J. Fish. Aquat. Sci., 59: 424-432 (2002).

Pomeroy, L. R. Primary Productivity of Boca Ciega Bay, Florida. Bull. Mar. Sci., 10: 1-10 (1960).

Ralston, S. Mortality rates of snappers and groupers. III Tropical snappers and groupers, pp. 375-404. In: Biology and Fisheries Management (Polovina, U., and S. Ralston, Eds.). Boulder: Westview Press (1987).

Rogers, M. W., and M. S. Allen. Use of ECOPATH with ECOSIM models to evaluate effects of stock enhancement programs. In: Florida Chapter AFS Annual Meeting, Ocala National Forest, March 2-7 (2008).

Salvanes, A. G. V., D. Aksnes, J. H. Fossa, and J. Giske. Simulated carrying capacities of fish in Norwegian fjords. Fish. Oceanogr., 4: 17-32 (1995).

Sibert, J., J. Hampton, P. Kleiber, and M. Maunder. Biomass, size, and trophic status of top predators in the Pacific Ocean. Science, 314: 1773-1776 (2006).

Silberschneider, V., and C. Gray. Arresting the decline of the commercial and recreational fisheries for mulloway (Argyrosomus japonicus). Cronulla: NSW Fisheries, 71 pp. (2005).

Silberschneider, V., and C. A. Gray. Synopsis of biological, fisheries and aquaculture-related information on mulloway Argyrosomus japonicus (Pisces: Sciaenidae), with particular reference to Australia. J. Appl. Ichthyol., 24: 7-17 (2008).

Silberschneider, V., C. A. Gray, and J. Stewart. Age, growth, maturity and the overfishing of the iconic sciaenid, Argyrosomus japonicus, in south-eastern, Australia. Fish. Res., 95: 220-229 (2009).

Smith, J. A., L. J. Baumgartner, I. M. Suthers, and M. D. Taylor. Generalist niche, specialist strategy: The diet of an Australian percichthyid. J. Fish Biol., 78: 1183-1199 (2011).

Stottrup, J. G., and C. R. Sparrevohn. Can stock enhancement enhance stocks? J. Sea Res., 57: 104-113 (2007).

Tatara, C. P., S. C. Riley, and B. A. Berejikian. Effects of hatchery fish density on emigration, growth, survival, and predation risk of 
natural steelhead parr in an experimental stream channel. N. Am. J. Fish. Manag., 31: 224-235 (2011).

Taylor, M. D. Spatial and temporal patterns of habitat use by three estuarine species of mysid shrimp. Mar. Freshw. Res., 59: 792-798 (2008).

Taylor, M. D., A. V. Fairfax, and I. M. Suthers. The race for space: Using acoustic telemetry to understand density-dependent emigration and habitat selection in a released predatory fish. Rev. Fish. Sci 21: 276-285 (2013).

Taylor, M. D., D. S. Fielder, and I. M. Suthers. Spatial and ontogenetic variation in the diet of wild and stocked mulloway (Argyrosomus japonicus, Sciaenidae) in Australian estuaries. Est. Coasts, 29: 785-793 (2006a).

Taylor, M. D., S. Fielder, and I. M. Suthers. Growth and viability of hatchery-reared Argyrosomus japonicus releases into open and semi-closed systems. Fish. Manag. Ecol., 16: 478-483 (2009).

Taylor, M. D., S. D. Laffan, D. S. Fielder, and I. M. Suthers. Key habitat and home range of mulloway (Argyrosomus japonicus) in a south-east Australian estuary: Finding the estuarine niche to optimise stocking. Mar. Ecol. Progr. Ser., 328: 237-247 (2006b).

Taylor, M. D., and D. Mazumder. Stable isotopes reveal post-release trophodynamic and ontogenetic changes in a released finfish, mulloway (Argyrosomus japonicus). Mar. Freshw. Res., 61: 302-308 (2010).

Taylor, M. D., P. J. Palmer, D. S. Fielder, and I. M. Suthers. Responsible estuarine finfish stock enhancement: An Australian perspective. $J$. Fish Biol., 67: 299-331 (2005).
Taylor, M. D., and R. F. Piola. Scale stocking checks to differentiate between wild and hatchery-reared mulloway (Argyrosomus japonicus). Fish. Manag. Ecol., 15: 211-216 (2008).

Taylor, M. D., and I. M. Suthers. A predatory impact model and targeted stocking approach for optimal release of mulloway (Argyrosomus japonicus). Rev. Fish. Sci., 16: 125-134 (2008).

Taylor, M. D., D. A. Ziemann, N. P. Brennan, K. M. Leber, and K. Lorenzen. Matching recruitment to carrying capacity: An evolving ecological basis for stocking density in open systems. In: Plenery Presentation, 2008 Australian Society for Fish Biology Annual Conference, Bondi, NSW, September 15-18 (2008).

Taylor, R. G., J. A. Whittington, and D. E. Haymans. Catch-and-release mortality rates of common snook in Florida. N. Am. J. Fish. Manag., 21: 70-75 (2001).

van der Veer, H. W., R. Berghahn, J. M. Miller, and A. D. Rijnsdorp. Recruitment in flatfish, with special emphasis on North Atlantic species: Progress made by the Flatfish Symposia. ICES J. Mar. Sci., 57: 202-215 (2000).

Walters, C. J., and F. Juanes. Recruitment limitation as a consequence of natural selection for use of restricted feeding habitats and predation risk taking by juvenile fishes. Can. J. Fish. Aquat. Sci., 50: 2058-2070 (1993).

Walters, C. J., and S. Martell. Fisheries ecology and management. Princeton, NJ:, Princeton University Press, 399 pp. (2004).

Wolff, M., and G. Cerda. Feeding ecology of the crab Cancer polyodon in La Herradura Bay, Northern Chile. 1. Feeding chronolgy, feed intake, and gross growth and ecological efficiency. Mar. Ecol. Progr Ser., 89: 213-219 (1992). 